\title{
New technique for showing the relation of tomographic myocardial perfusion images obtained with thallium-201 to the coronary arteries
}

\author{
CHRISTOPHER J GIBSON, * ELSIE E LAIRD, $†$ E DAVID WILLIAMS, $\dagger$ \\ A RAJATHURAI, $\ddagger$ BRAJ MITTRA, $\ddagger$ DONALD RANKIN $\dagger$ \\ From the Regional Medical Physics Department, ${ }^{\star}$ Durham Unit, Dryburn Hospital, Durham; and \\ $\dagger$ Sunderland Unit, Sunderland District General Hospital; and the $\ddagger D e p a r t m e n t$ of Medicine, Sunderland \\ District General Hospital, Sunderland, Tyne and Wear
}

SUMMARY A new technique has been developed for presenting myocardial tomograms that allows the observer to perceive the shape of the thallium-201 distribution directly. The surface of the myocardium was found by applying an interactive thresholding technique to a set of conventional transverse slices. Computer graphics techniques were used to display a shaded image of that surface on a television screen, showing the three dimensional shape of the myocardial surface from any chosen aspect. A set of normal preserved coronary arteries was digitised, and using scaling and transformation techniques these arteries were mapped on to the myocardial tomograms and a shaded surface image produced with superimposed coronary arteries. This provided a familiar anatomical framework for locating perfusion defects. Its value in identifying various diseased vessels was confirmed by a comparison of the tomographic findings with the angiographic findings in five individual cases.

Thallium-201 perfusion scintigraphy is now a well established technique for imaging the myocardium. ${ }^{12}$ Its use is advocated in patients with atypical chest pain for diagnosing possible coronary artery disease. ${ }^{3-5}$ The interpretation of thallium201 images is, however, difficult and requires considerable experience to obtain reproducible results, and considerable interobserver variation has been found. ${ }^{67}$ This situation led to the development of semiquantitative methods for analysing thallium scans ${ }^{8-10}$ and may also be responsible for the poor correlation reported by some authors between the site of disease as determined from scans and that of coronary artery stenoses found by angiography. ${ }^{1112}$ Further studies to improve the accuracy of localisation of disease have compared semiquantitative results with empirically derived normal ranges. ${ }^{1314}$ The scintigraphic appearances of specific coronary artery stenoses have been studied extensively and many patterns identified ${ }^{14}$; with experienced ob-

Requests for reprints to Dr E D Williams, Regional Medical Physics Department, Sunderland District General Hospital, Kayll Road, Sunderland, Tyne and Wear SR4 7TP.

Accepted for publication 27 June 1985 servers these methods gave accurate localisation of disease. ${ }^{15}$

Rotating gammacamera tomography has been shown to be the best imaging technique generally available for thallium-201 scintigraphy of the myocardium. ${ }^{16-18}$ The use of tomograms is an important step forward towards the location of arterial disease, with relatively good results being obtained in one or two vessel disease. ${ }^{19}$ We have previously established a tomographic technique using both exercise and resting scans and have shown good agreement with exercise electrocardiographic results, good agreement between qualitative and semiquantitative assessment, and an absence of equivocal results. ${ }^{20}$ We now report a method for relating scintigraphic findings to the coronary arteries. We believe that this will be a useful step forward towards the use of thallium-201 for localising coronary artery disease.

\section{Patients and methods}

Patients underwent a symptom limited exercise electrocardiographic test in accordance with a Bruce protocol. Once peak stress had been achieved in the 

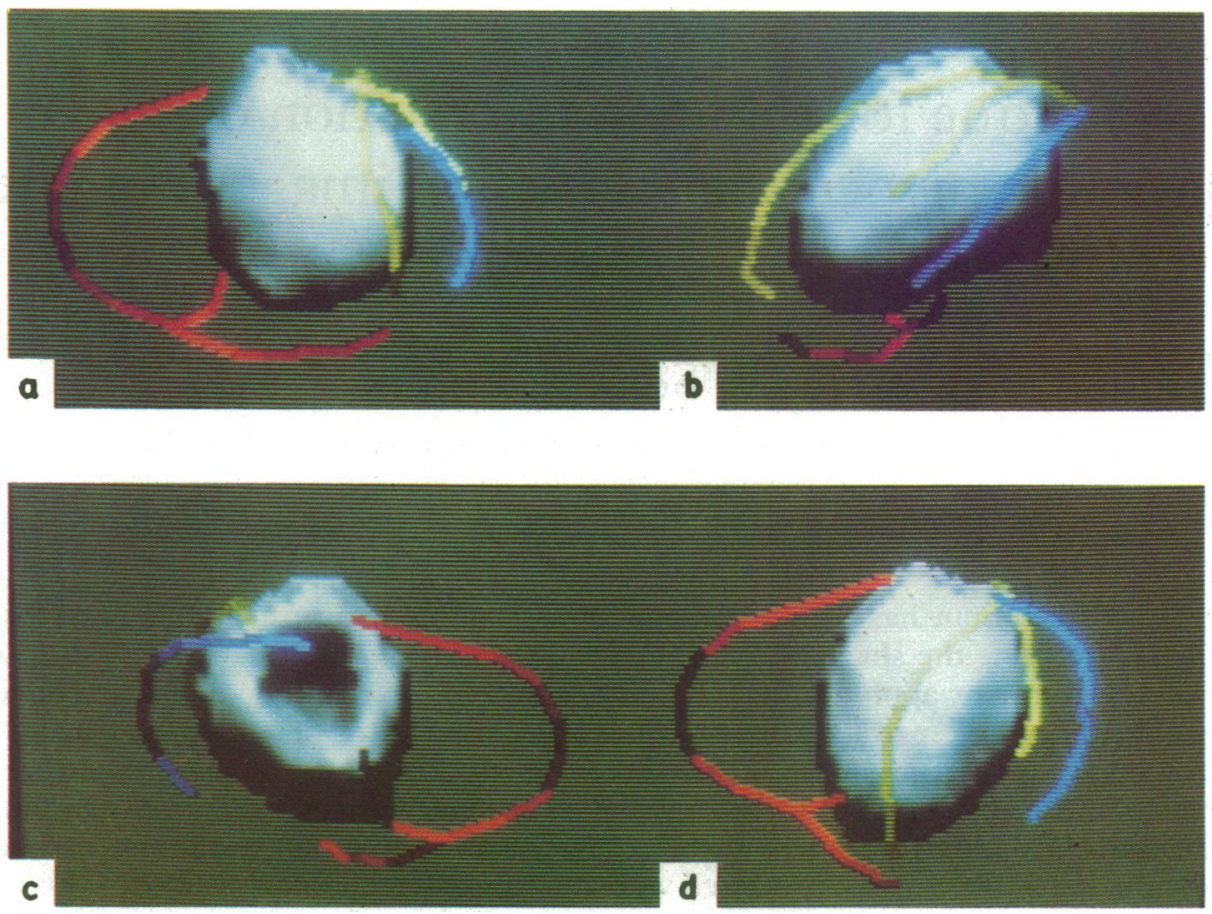

Fig. 1 Three dimensional shaded image representations of thallium-201 uptake in a normal myocardium (case 1) viewed from (a) the anterior, (b) the left lateral, (c) the right posterior oblique, and $(d)$ the left anterior oblique positions with the coronary arteries and their major branches superimposed (right coronary artery in red, left descending in yellow, circumflex in blue).

exercise test $80 \mathrm{MBq}$ thallium-201 thallous chloride was injected and exercise continued for a further minute. Patients were then quickly transferred for imaging, which began within five minutes of the end of exercise. An IGE 400 AT gammacamera with a DEC Gamma-11 computer system was used for tomographic imaging. ${ }^{21}$ Data were acquired for $40 \mathrm{~s}$ at each of 32 equally spaced positions over a $180^{\circ}$ arc from left posterior oblique to right anterior oblique. A low energy general purpose collimator was used and the pulse height analyser window set at 55-90 $\mathrm{keV}$. Tomography was repeated after four hours rest to allow the thallium-201 to redistribute to the resting perfusion pattern. The image data were filtered with a Metz count dependent prefilter ${ }^{22}$ and a magnified reconstruction performed by back projection (NucMed software package, Analogic Corp, Wakefield, Massachusetts, USA). The pixel size in reconstructed images was equivalent to $3 \mathrm{~mm}$. This image processing was considered subjectively to give the best quality tomographic images.

Transverse section data were transferred to a Link Dyanne computer system via magnetic tape and were used to construct a three dimensional representation of the myocardial uptake. A count thresh- old level was selected interactively, and a computer model of the resulting myocardial distribution created by stacking adjacent transverse sections. Only pixels with count values greater than the threshold level were considered to be part of the model. From a set of up to 64 transverse sections ( $3 \mathrm{~mm}$ nominal thickness) each of $64 \times 64$ pixels $(3 \times 3 \mathrm{~mm})$, the myocardium was modelled by an array of $64 \times 64 \times$ 64 bits, where each bit was set only if the corresponding pixel exceeded the threshold level. The time required to create this binary model from a set of tomograms was $1.5 \mathrm{~s}$ per slice or typically $45 \mathrm{~s}$ per study. Note that the model needed to be created once only and was then stored on disk. This model was displayed as if illuminated by a light source located above the observer's head and angled down on the model. For all visible points on the model a grey scale value was calculated from the local surface orientation. The resulting shaded surface image presents information about the shape of three dimensional objects in a two dimensional form. ${ }^{23}$ By rotating and tilting the model the myocardial distribution may be viewed from any angle, thus allowing the observer to perceive directly the three dimensional distribution of perfused myocardium. The 

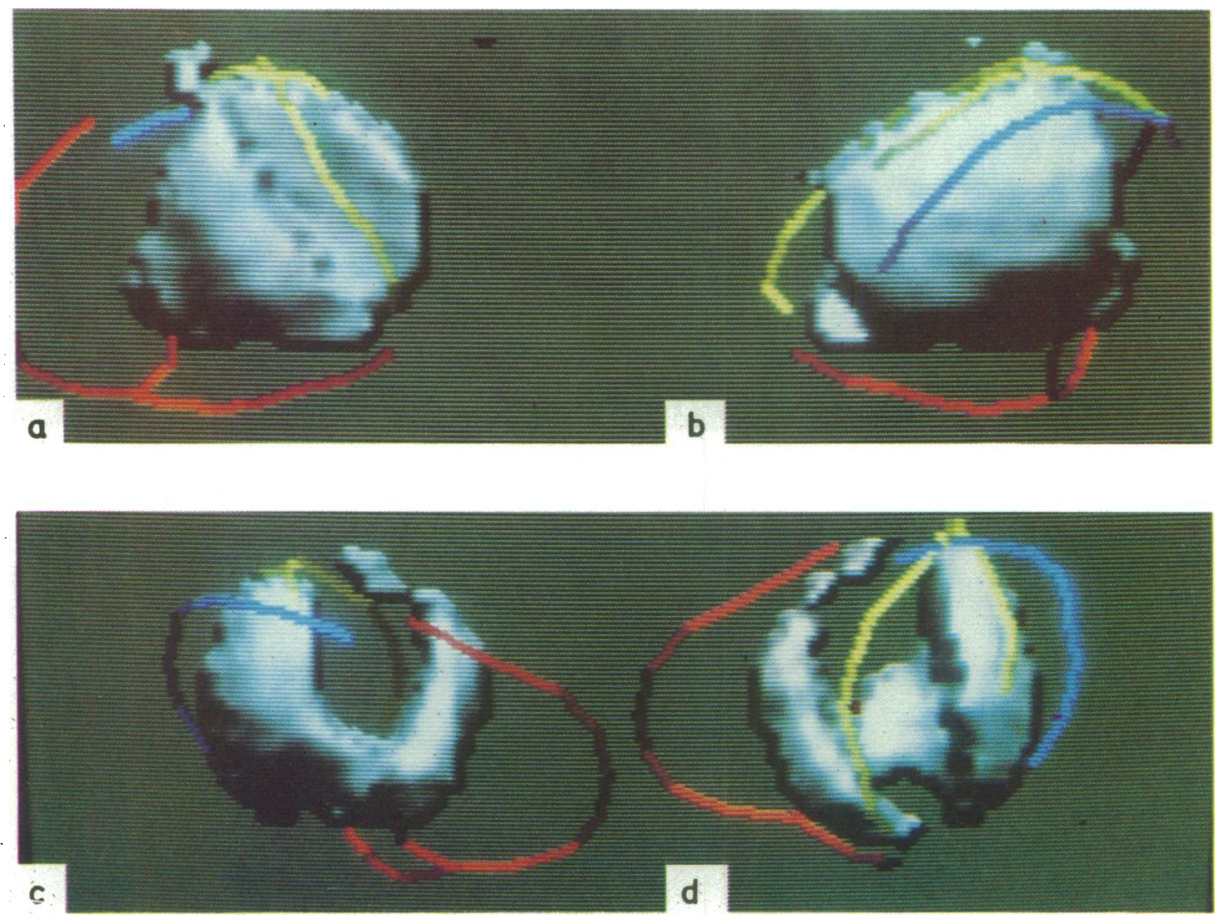

Fig. 2 Thallium-201 images at rest viewed from (a) the anterior, (b) the left posterior oblique (c), the right posterior oblique, and (d) the left anterior oblique positions showing a large perfusion defect in the anterior wall, coincident with the left anterior descending artery and therefore indicating the site of $a$ previous myocardial infarction (case 2). Colour coding of coronary arteries as in Fig. 1.

time taken to rotate the model and to display a shaded surface image depended on myocardial size and ranged from 4 to $6 \mathrm{~s}$ to rotate or tilt the model and from 13 to $24 \mathrm{~s}$ to calculate and display the shaded surface image. Although faster execution would be desirable, these times are sufficiently short to allow the program to be used interactively.

To provide anatomical reference points, the locations of the coronary arteries and their major branches were added to the display. A cast of coronary arteries was obtained from a normal necropsy specimen, and the major arteries were digitised in three dimensions using a reflex metrograph (Ross Instruments). A simple fitting procedure was used to scale these arteries on to the computer model of myocardial uptake. A hidden surface algorithm ensured that only the visible portions of the coronary arteries were displayed when the myocardium was observed from different aspects.

Several methods were used for viewing the result. Arteries were distinguished one from another and from myocardium by using a different colour for each artery on a colour video monitor and superimposing the arteries on a grey shaded image of myocardial uptake. The location of arteries could be perceived by presenting multiple views of the image model from several different aspects simultaneously (Figs. 1-5). An alternative method was a rapid sequential display of views with small angular displacements so that motion parallax improved the three dimensional perception. ${ }^{24}$ Finally, stereo pair images can be constructed by creating two images with a small angular displacement $\left(10^{\circ}\right)$ and viewing these as transparencies with an appropriate viewer. Only the first method was considered suitable for printed publication.

\section{Results}

\section{CASE REPORTS}

Case 1 (normal) -A man aged 46 was admitted to hospital after a "collapse." Initially, he manifested sinus tachycardia and later sinus bradycardia. An exercise electrocardiogram performed to rule out ischaemic heart disease was equivocal and was therefore repeated and combined with a thallium scan. During the exercise test he exercised well into stage VII with no chest pain and no electrocardiographic changes. Coronary angiography was therefore not sought. The thallium tomograms showed no evi- 

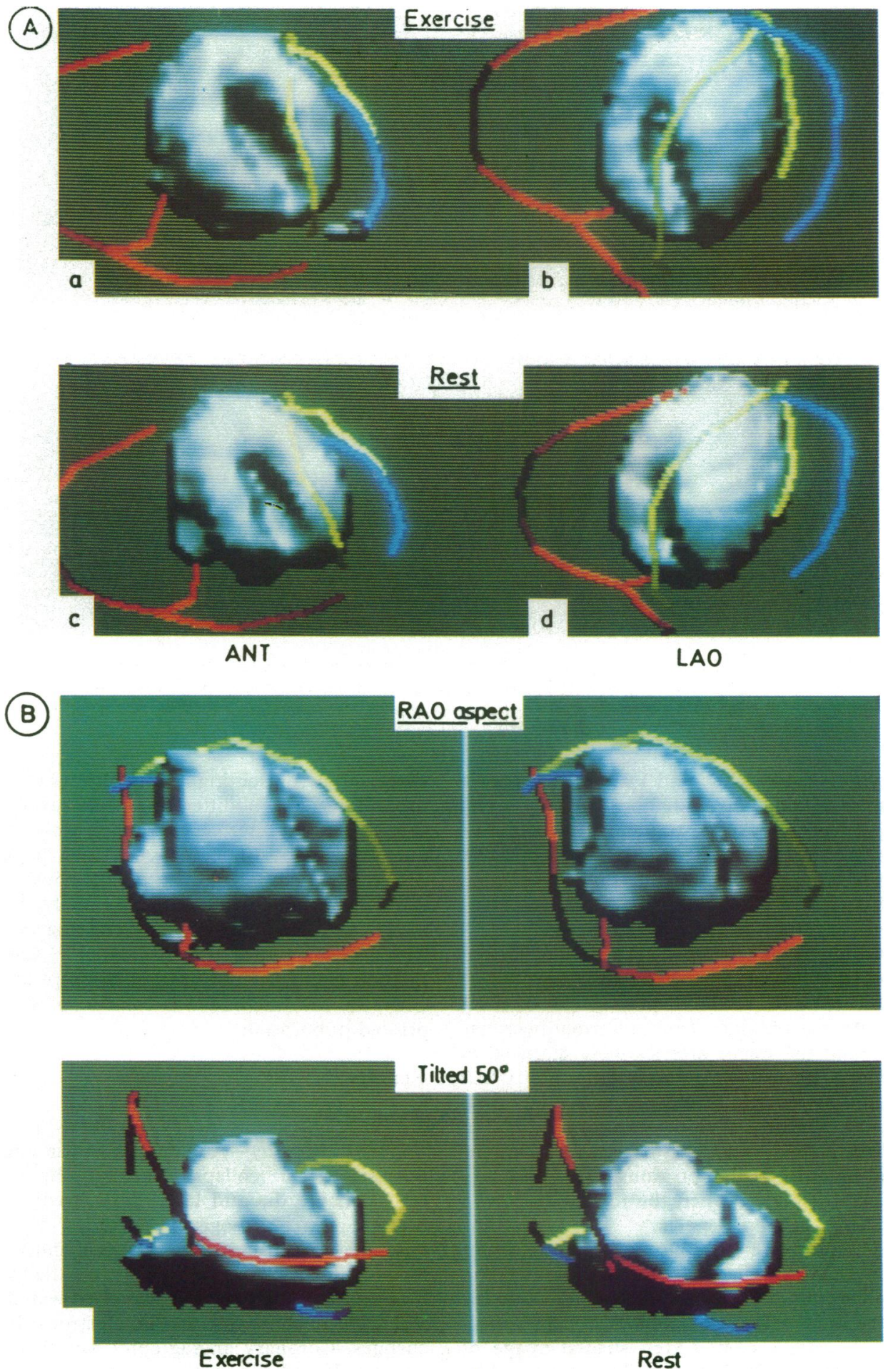

Fig. 3 Thallium-201 images viewed from the anterior (ANT) and left anterior oblique ( $L A O)$ positions showing $(A)$ apical defect both on exercise ( $a$ and $b$ ) and at rest ( $c$ and d) corresponding to distal left anterior descending artery. (B) The right anterior oblique (RAO) view shows a defect on exercise in the right coronary artery territory. Colour coding of coronary arteries as in Fig. 1. 

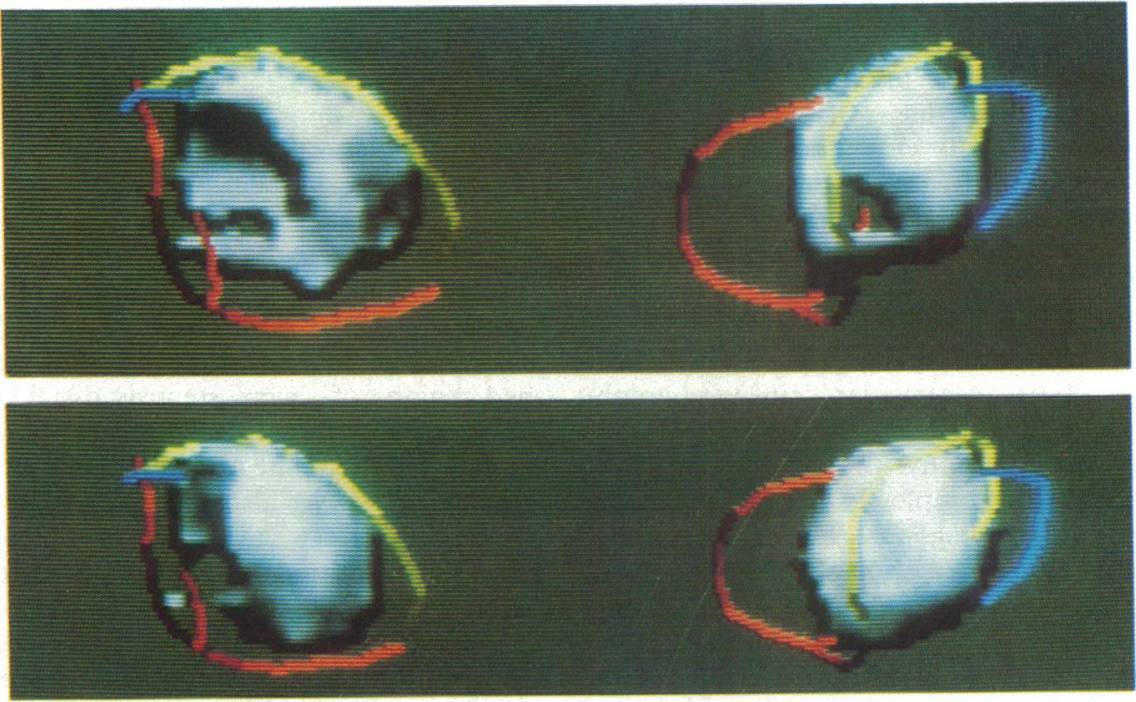

\section{RAO}

LAO

Fig. 4 Thallium-201 images in the right anterior oblique (RAO) and left anterior oblique (LAO) positions on exercise (top) and at rest (bottom) (case 4). Two defects are seen on exercise in the septal and anterior regions, both of which are perfused at rest. The defects do not correspond directly to the major arteries, which indicates that some of their branches or distal portions are diseased. Colour coding of coronary arteries as in Fig. 1.
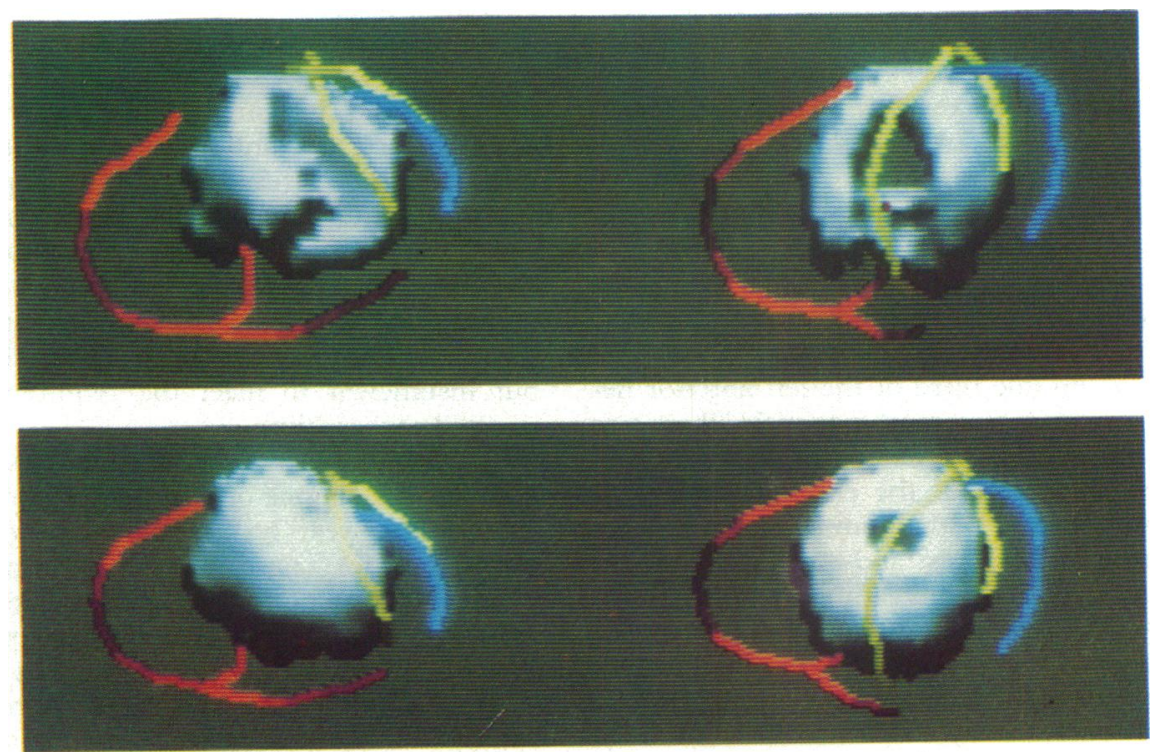

ANT

\section{LAO}

Fig. 5 Thallium-201 images on exercise (top) and at rest (bottom) viewed from the anterior (ANT) and left anterior oblique ( $L A O$ ) positions in a patient (case 5) with ischaemia. The large defect on exercise extends along the line of the left anterior descending artery and continues right under the left ventricle. There is a second small defect on the inferior surface indicating right coronary artery disease also. Colour coding of coronary arteries as in Fig. 1. 
dence of ischaemia, and three dimensional reconstruction showed no defects on exercise or resting images. Thus each of the investigations confirmed the absence of ischaemic heart disease (Fig. 1).

Case 2 (infarct) - A 38 year old man with a previous history of anteroseptal myocardial infarction presented again four months later with chest pain that could have been anginal in nature and was treated with beta blockers and nitrates. An exercise electrocardiogram was terminated at stage IV because of chest pain, but no changes were evident in the tracing. Left ventricular cineangiography showed the anteroapical region to be akinetic, and on coronary arteriography the left anterior descending artery was completely occluded just beyond the large first diagonal. The thallium scan showed a large apical defect on the exercise tomograms but a slight uptake at the apex on the resting images. This indicated an apical myocardial infarction, with a possible ischaemic area. The three dimensional display (Fig. 2) showed a large left ventricle with a major defect in the superior/apical surface, almost exactly coincident with the left anterior descending artery after the first diagonal branch. Rest and exercise images were similar, except for possible defect enlargement seen on the exercise image. The findings of the thallium scan were therefore in good agreement with the coronary angiography report.

Case 3 (infarct and coronary artery disease)-A 36 year old man had had extensive anterior wall myocardial infarction one year previously. His continuing chest pain was treated with a beta blocker (atenolol), a calcium antagonist (nifedipine), and nitrates. An exercise electrocardiogram was terminated at stage II because of chest pain and dizziness. There was ST elevation and $T$ wave inversion in the anteroseptal leads. Left ventriculography showed apical akinesia and arteriography showed a tight stenosis in the middle third of the left anterior descending artery and its second diagonal. There was also fairly diffuse disease affecting the marginal and posterolateral branches of the circumflex and the right coronary artery. A thallium scan showed decreased uptake on both rest and exercise images in the apicoseptal region, indicating myocardial infarction there. Also an area of decreased uptake was seen in the inferoseptal region on exercise, which had normal uptake at rest, indicating ischaemia. The three dimensional display confirmed these findings by showing a defect in the inferoapical region that extended to the superior surface (Fig. 3) and was reasonably coincident with the distal portion of the left anterior descending artery and an inferoseptal defect on exercise in the territory of the right coronary artery.
Case 4 (coronary artery disease)-A man aged 50 years had mild hypertension and a four month history of angina of effort, which was gradually getting worse and was not controlled by treatment with atenolol and chlorthalidone, nitrates, and nifedipine. The exercise electrocardiogram showed ST segment depression in V5 leads at stage III. The coronary angiogram indicated a blockage in the right coronary artery beyond its right ventricular branch, but the distal part of the vessel was filled retrogradely. The circumflex artery was the dominant vessel, but this had regions of severe stenosis distal to the obtuse marginal branch and proximal to the posterior descending artery. The mid portion of the obtuse marginal branch was also diseased. The left anterior descending artery had regions of stenosis both proximal and distal to the first septal branch and proximal to the large second diagonal. The second diagonal branch showed moderate stenosis in the mid portion and the left anterior descending artery itself was blocked distal to this branch, although there was some retrograde filling. The thallium scan showed defects on exercise in the septum and inferolateral regions which had normal uptake on the later (resting) images. The three dimensional representation indicated two defects on exercise in the anterior and septal walls (Fig.4). These could not be directly related to the main coronary arteries but appeared to be in the territories of the left anterior descending or right coronary artery or both. Neither defect was seen at rest. The defects seen on the thallium scan did not correspond directly to the main coronary arteries, and this is consistent with the fairly extensive disease found at angiography to involve the distal portions and branches of the main coronary arteries. Thus the collateral circulation shown on the coronary arteriogram to supplement that of the distal right coronary and left anterior descending arteries would appear to be adequate at rest but insufficient to meet the requirements of the stressed myocardium.

Case 5 (coronary artery disease)-A 52 year old man had had angina of effort and sometimes at rest for about one year: he had had two previous hospital admissions for chest pain. The symptoms were treated with atenolol and chlorthalidone, nitrates, and nifedipine. An exercise electrocardiogram showed ST segment depression in the inferolateral leads at stage III. He is awaiting coronary angiography. Thallium scans showed an apical defect on exercise, which had normal uptake on the later (resting) image. The three dimensional display also showed a large defect on the exercise image, extending along the line of the left anterior descending artery from approximately the second diagonal branch. This defect persisted as a very small abnor- 
mality on the resting image. The defect extended right under the left ventricle, with a second small defect in the inferior surface. This suggests disease of the right coronary artery also. Although the findings have not yet been confirmed by coronary angiography, the three dimensional reconstructions unequivocally indicated the site of disease to be in the left anterior descending artery.

\section{Discussion}

Presentation has long dogged the acceptance of nuclear medicine images by doctors, both because images commonly lack anatomical reference points and because a functional rather than an anatomical image is presented. Thus recognition of image features can be difficult for the uninitiated. In nuclear cardiology further difficulties have been presented by the introduction of parametric imaging, ${ }^{25}$ which is even further removed from common ideas of anatomy.

The method described in this paper is an attempt to reverse this process by presenting images of functioning myocardium in which the spatial relations of the different parts of myocardium, and their relative function, are clearly discernible and in which the appropriate anatomical reference points are provided by superimposing the coronary arteries. We hope that by this means we shall be able to establish more clearly the relation between myocardial perfusion defects, at rest and during exercise, and the site of coronary artery disease.

Several authors have described shaded surface techniques for displaying three dimensional information. ${ }^{26-28}$ Applications have included surgical planning, ${ }^{29}$ radiotherapy planning, ${ }^{30}$ and an evaluation of complex musculoskeletal anatomy. ${ }^{31}$ There have been only a few reports of applications using radionuclide tomography. ${ }^{2332}$ Our technique differs from previous methods in two ways. Firstly, for the chosen viewing direction a two dimensional image array was calculated, each pixel of which contained the value of the distance from a plane of each visible point on the three dimensional model. The shading algorithm was then applied to this array to create the final image. The algorithm includes some surface smoothing and a two dimensional local polynomial fit to estimate the orientation of the surface normal at all points in the image, which is necessary before illumination by the imaginary light source. Despite the relatively coarse sampling of radionuclide tomograms compared with other modalities this procedure can produce smooth surface images rather than the irregular surfaces shown by simpler techniques. Because the shading algorithm operates on two dimensional arrays it can incorporate this level of complexity without also requiring a long exe- cution time. Secondly, we have added anatomical information to the display in the form of superimposed coronary arteries. This not only provides a familiar anatomical framework for viewing the myocardium and may thus aid correct identification of the location of arterial disease but also enhances the perception of depth.

Two assumptions have to be made in order to create our three dimensional images. Firstly, it is necessary to assume that the distribution of thallium-201 contains definite areas of uptake that may be enclosed by a surface, corresponding to an isocount contour. In practice the uptake often varies continuously from lower to higher values. A simple thresholding technique can distinguish the areas of appreciably reduced uptake but will probably fail to detect small areas of only slightly reduced uptake. Secondly, the spatial distribution of the coronary arteries corresponds to that of one normal subject. The arteries displayed on each image have been scaled and rotated to match the individual myocardial model, but they should be interpreted as only indicating the probable site of the actual coronary arteries.

We suspect that the accuracy achievable by perfusion scintigraphy in detecting one or two vessel disease may be better than has previously been reported. ${ }^{19}$ Localisation of coronary artery disease is important in order to determine whether patients are suitable for coronary artery bypass graft surgery. ${ }^{33}$ In addition, the method should prove useful for the non-invasive follow up of patients after surgery who produce new symptoms and for assessing the success of coronary angioplasty.

We thank R Blair, Y Ennew, C Taylor, K Turner, and J Russell for their technical assistance, and cardiologists at the Regional Cardiothoracic Centre, Freeman Hospital, Newcastle upon Tyne, for the angiography reports.

\section{References}

1 Strauss HW, Pitt B. Evaluation of cardiac function and structure with radioactive tracer techniques. Circulation 1978; 57: 645-54.

2 Wainwright RJ, Maisey MN. Cardiac imaging, Part 1, Myocardial perfusion scintigraphy. Hospital Update 1978; 22: 623-38.

3 Iskandrian AS, Wasserman LA, Anderson GS, Hakki H, Segal BL, Kane S. Merits of stress thallium-201 myocardial perfusion imaging in patients with inconclusive exercise electrocardiograms: correlation with coronary arteriograms. Am $\mathcal{F}$ Cardiol 1980; 46: 553-8.

4 Fletcher JW, Walker KE, Witztum KF, et al. Diagnosis of coronary artery disease with 201-Tl. Radiology 
1978; 128: 423-7.

5 McCarthy DM, Blood DK, Sciacca RR, Cannon PJ. Single dose myocardial perfusion imaging with thallium-201: application in patients with nondiagnostic electrocardiographic stress tests. Am $\mathcal{F ~ C a r -}$ diol 1979; 43: 899-906.

6 Trobaugh GB, Wackers FJT, Sokole EB, DeRouen TA, Ritchie JL, Hamilton GW. Thallium-201 myocardial imaging: an interinstitutional study of observer variability. $₹$ Nucl Med 1978; 19: 359-63.

7 Okada RD, Boucher CA, Kirshenbaum HK, et al. Improved diagnostic accuracy of thallium-201 stress test using multiple observers and criteria derived from interobserver analysis of variance. Am $\mathcal{F}$ Cardiol 1980; 46: 619-24.

8 Francisco DA, Collins SM, Go RT, Erhardt JC, Van Kirk OC, Marcus ML. Tomographic thallium-201 myocardial perfusion scintigrams after maximal coronary artery vasodilation with intravenous dipyridamole. Circulation 1982; 66: 370-9.

9 Buell U, Kleinhaus E, Seiderer M, Strauer BE. Quantitative assessment of thallium-201 images. Cardiovasc Radiol 1979; 2: 183-93.

10 Berger BC, Watson DD, Taylor GJ, et al. Quantitative thallium-201 exercise scintigraphy for detection of coronary artery disease. $\mathcal{F} \mathrm{Nucl}$ Med 1981; 22: 585-93.

11 McKillop JH, Murray RG, Turner JG, Bessent RG, Lorimer AR, Greig WR. Can the extent of coronary artery disease be predicted from thallium-201 myocardial images? f Nucl Med 1979; 20: 715-9.

12 Rigo P, Bailey IK, Griffith LSC, et al. Value and limitations of segmental analysis of stress thallium myocardial imaging for localization of coronary artery disease. Circulation 1980; 16: 973-81.

13 Burow RD, Pond M, Schafer AW, Becker L. "Circumferential profiles". A new method for computer analysis of thallium-201 myocardial perfusion images. $\mathcal{F} \mathrm{Nucl}$ Med 1979; 20: 771-7.

14 Wainwright RJ. Scintigraphic anatomy of coronary artery disease in digital thallium-201 myocardial images. Br Heart $\mathcal{f}$ 1981; 46: 465-77.

15 Wainwright RJ, Maisey MN, Sowton E. Segmental quantitative analysis of digital thallium-201 myocardial scintigrams in diagnosis of coronary artery disease: Comparison with rest and exercise electrocardiography and coronary arteriography. $\mathrm{Br}$ Heart $\mathcal{f} 1981$; 46: 478-85.

16 Tamaki N, Mukai T, Ishii Y, et al. Clinical evaluation of Thallium-201 emission myocardial tomography using a rotating gamma camera: comparison with sevenpinhole tomography. $\mathcal{f}$ Nucl Med 1981; 22: 849-55.

17 Ritchie JL, Larsson S, Israelson A, et al. Single photon tomographic imaging of a standard heart phantom with 201Tl: a gamma camera based system. Eur $\mathcal{F} \mathrm{Nucl}$ Med
1982; 7: 254-9.

18 Myers MJ, Sokole EB, de Bakker J. A comparison of rotating slant hole collimator and rotating camera for single photon emission tomography of the heart. Phys Med Biol 1983; 28: 581-8.

19 Tamaki N, Yonekura Y, Mukai T, et al. Segmental analysis of stress thallium myocardial emission tomography for localization of coronary artery disease. Eur $\mathcal{F}$ Nucl Med 1984; 9: 99-105.

20 Laird EE, Rajathurai A, Williams ED, Mittra B, Rankin D. Quantitative analysis of rotating gamma camera thallium-201 scintigrams of myocardium. Nuclear Medicine Communications 1984; 5: 577-86.

21 Larsson SA. Gamma camera emission tomography. Acta Radiologica 1980; suppl 363.

22 King MA, Schwinger RB, Doherty PW, Penney BC. Two-dimensional filtering of SPECT images using the Metz and Wiener filters. $\mathcal{F}$ Nucl Med 1984; 25: $1234-40$.

23 Gibson CJ. A new method for the three dimensional display of tomographic images. Phys Med Biol 1983; 28: 1153-7.

24 Williams ED. Three-dimensional radionuclide images [Letter]. $\mathcal{F ~ N u c l ~ M e d ~ 1 9 8 1 ; ~ 2 2 : ~} 193$.

25 Houston AS, Elliott AT, Stone DL. Factorial phase imaging: a new concept in the analysis of first-pass cardiac studies. Phys Med Biol 1982; 27: 1269-77.

26 Herman GT, Liu HK. Three dimensional display of human organs from computed tomograms. Computer Graphics and Image Processing 1979; 9: 1-21.

27 Cook LT, Dwyer SJ, Batnitzky S, Lee KR. A three dimensional display system for diagnostic imaging applications. IEEE Computer Graphics and Applications 1983; 3: 13-9.

28 Udupa JK. Display of 3-D information in discrete 3-D scenes produced by computerised tomography. Proceedings of the IEEE 1983; 71: 420-31.

29 Vannier MW, Marsh JL, Warren JO. Three dimensional CT reconstruction images for craniofacial surgical planning and evaluation. Radiology 1984; 150: 179-84.

30 Bloch P, Udupa JK. Application of computerised tomography to radiation therapy and surgical planning. Proceedings of the IEEE 1983; 71: 351-5.

31 Totty WG, Vannier MW. Complex musculo-skeletal anatomy: analysis using three dimensional surface reconstruction. Radiology 1984; 150: 173-7.

32 Minato K, Mukai T, Yamamoto K, et al. Three dimensional display of single photon ECT imaging. Proceedings of the 3rd World Congress of Nuclear Medicine and Biology. 1982. Oxford: Pergamon Press, 1983: 3651.

33 Hampton JR. Coronary artery bypass grafting for the reduction of mortality: an analysis of the trials. $\mathrm{Br} \mathrm{Med}$ f 1984; 289: 1166-70. 